\title{
Child Victim Services in the Time of COVID-19: New Challenges and Innovative Solutions
}

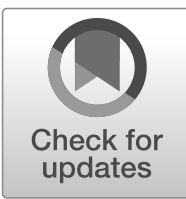

\author{
Chad Posick $^{1}$ (D) April A. Schueths ${ }^{2}$ - Cary Christian ${ }^{3}$. Jonathan A. Grubb ${ }^{1}$. \\ Suzanne E. Christian ${ }^{4}$
}

Received: 18 May 2020 / Accepted: 8 June 2020 /

Published online: 14 June 2020

(C) Southern Criminal Justice Association 2020

\begin{abstract}
The impact of COVID-19 has been felt by all facets of the criminal justice system and victim services agencies. The ability to monitor and report maltreatment has been severely limited for organizations that work with children of abuse and neglect; this is particularly troubling given that abuse and neglect are likely to rise during times of distress and turmoil. The purpose of this paper is to discuss the importance of organizations that work with children exposed to maltreatment, highlight the novel approach of Child Advocacy Services, SEGA, Inc. (CASSEGA), the sponsoring agency for Court Appointed Special Advocates (CASA) and the Ogeechee Visitation Centers, in rural southeast Georgia and how the COVID-19 pandemic has challenged this work, and develop strategies that can be put into place to alleviate these challenges for other child-serving organizations.
\end{abstract}

Keywords Abuse · COVID-19· Neglect · Technology · Victim services

Chad Posick

cposick@georgiasouthern.edu

April A. Schueths

aschueths@georgiasouthern.edu

Cary Christian

pchristian@georgiasouthern.edu

Jonathan A. Grubb

jgrubb@georgiasouthern.edu

Suzanne E. Christian

suze@casaogeechee.org

Extended author information available on the last page of the article 


\section{Introduction}

The health and well-being of children and adolescents remain significant concerns in the US and abroad. Lifetime estimates of child maltreatment differ across race, gender, and socioeconomic status. Recent estimates from the National Child Abuse and Neglect Data System (NCANDS) of confirmed and investigated maltreatment range from a high of 53\% in African Americans and a low of 10.2\% among Asian/Pacific Islanders. The lifetime prevalence for Hispanics is $32 \%, 28.2 \%$ for Whites, and $23.4 \%$ for Native Americans. On average, $37.4 \%$ of all children have received some child protective service investigation by the age of 18 (Kim, Wildeman, Jonson-Reid, \& Drake, 2017).

The perpetrators of child abuse are often parents and siblings, who live under the same roof as the victim. When societal factors impact the family unit, children are often the target of maltreatment, and when resources are low, neglect becomes worse. There is a known relationship between poverty and child abuse (Cherry \& Wang, 2016; Drake \& Pandey, 1996; Pelton, 2015; Yang, 2015; Lee, Romich, Kang, Hook, \& Marcenko, 2017) and between poverty and re-referral to child welfare agencies after reunification (Connell, Bergeron, Katz, Saunders, \& Tebes, 2007; Kahn \& Schwalbe, 2010). Despite overall rates of child maltreatment consistently being high, those rates can increase in times of mass illness and economic decline. For instance, an increase in the risk of child abuse, maltreatment, and neglect was documented in association with the Great Recession (Schneider, Waldfogel, \& Brooks-Gunn, 2017; Brooks-Gunn, Schneider, \& Waldfogel, 2013). This literature suggests that the economic impact of COVID-19 will introduce a series of added stressors to already troubled homes.

First, households living in poverty are likely to experience reduced income due to shelter-at-home requirements and the closing of many establishments that employ lowincome workers. Second, the requirement to stay at home will add to tensions that already exist between family members or create tension where none existed before, especially in homes with an adult male present and unemployed (Cherry \& Wang, 2016; Schneider et al., 2017). Home-schooling and other childcare responsibilities add to parental frustrations and create additional flash points for maltreatment. Since schools have been closed, reports of child maltreatment have dropped around the US (Schmidt \& Natanson, 2020). Children are no longer physically monitored by a wide range of mandated reporters. As a result, signs of increased abuse are either impossible to see or recognition will be deferred until after distancing requirements lapse resulting in additional damage inflicted upon the child. Reports from emergency rooms and child advocates (Schmidt \& Natanson, 2020; Woodall, 2020) already indicate an increase in serious injuries of child abuse.

Unlike child maltreatment reports, domestic violence reports have increased since the pandemic. For example, in Savannah, Georgia, the Savannah Police Department has witnessed an increase in calls for domestic violence. Much of this increase, about $70 \%$ of all calls, is due to first-time callers. This has led to a backlog in the District Attorney's Office of temporary protective orders (Evans, 2020). The New York Times has reported similar findings worldwide (Taub, 2020). Locations in Spain, France, Russia, and China experienced increases in domestic violence calls in the time of COVID-19. While these calls often center on violence, psychological and emotional abuse are also seen to be on the rise. Along with backlogs in temporary protective orders, courts are bottlenecking, delaying court proceedings. Many countries are 
converting vacant hotel rooms into shelters for domestic violence victims. Similar situations have followed other disasters, including the eruption of Mount Saint Helens, Hurricane Katrina, and the Black Saturday Bushfires in Australia (see also Campbell, 2020).

The impact of COVID-19 has been felt by all facets of the criminal justice system and victim services agencies. The ability to monitor and report maltreatment has been severely limited for organizations that work with children of abuse and neglect; this is particularly troubling given that abuse and neglect are likely to rise during times of distress and turmoil. This paper discusses the importance of organizations that work with children exposed to maltreatment, highlighting the novel approach of Child Advocacy Services, SEGA, Inc. (CASSEGA), the sponsoring agency for Court Appointed Special Advocates (CASA) and the Ogeechee Visitation Centers, in rural southeast Georgia and how the COVID-19 pandemic has challenged this work, and what strategies can be put into place to alleviate these challenges for other child-serving organizations.

\section{Child Victim Services}

Child Protective Services (CPS) is required to investigate suspected cases of abuse and neglect as well as provide prevention and post-investigation services, depending on the needs of the family (U.S. Department of Health \& Human Services, 2020). In 2018, 2 million children received preventative services, while 1.3 million children received post-investigation services from CPS. Post-investigation services for child victims frequently involve case management, concrete services, such as finances and transportation, parent training, and mental health counseling.

One of the most well-known post-investigative services is foster care. Approximately 437,283 children were living in foster care in the fall of 2018 (Administration for Children and Families, 2019); this is only $4 \%$ of children with substantiated maltreatment cases as placing children in out-of-home care is considered a temporary, potentially damaging, last option. Yi and Wildeman (2018, p. 39) point out emerging research that posits foster care youth, "are more likely than others to experience incarceration and that incarcerated adults are disproportionately likely to have been in foster care, suggesting a foster care-to-prison pipeline." Disparities in the child welfare system point to the need for effective service interventions for children and youth already living in foster care (see also Felix, Agnich, \& Schueths, 2017).

Reunification with biological parents, when safe for foster children, is the primary goal and is often facilitated through supervised visitation along with parenting coaching. A systematic review of the literature found that foster children who have frequent, meaningful face-to-face contact with their parents with family support can increase parents ability to regulate their emotions and improve the relationship between child and parent (Bullen, Taplin, McArthur, Humphreys, \& Kertesz, 2017). Familyfocused interventions have also been found to increase parent's engagement and may lead to an increase in family reunification (Maltais, Cyr, Parent, \& Pascuzzo, 2019). More research is needed about the best way to provide supervised visitation (Bullen et al., 2017).

The pandemic presents a significant challenge by preventing families with children in foster care from attending supervised visitation with their children and visitation 
among siblings causing additional trauma to the child in care (McWey \& Mullis, 2004; Cantos, Gries, \& Slis, 1997; Wojciak, Range, Gutierrez, Hough, \& Gamboni, 2018). Moreover, supervised visitation can be a financial burden as many families cannot afford to pay out-of-pocket for this service. The recession associated with the COVID19 pandemic will likely create budgetary problems for organizations tasked with providing services to abused children, foster parents, and biological parents seeking reunification (Boylan \& Ho, 2017; Graaf, Hengeveld-Bidmon, Carnochan, Radu, \& Austin, 2016).

\section{Court Appointed Special Advocates}

Nationally, Court Appointed Special Advocates (CASA) serves the majority of foster care children and strives to advocate for $100 \%$. The first Court Appointed Special Advocates for Children (CASA), a nonprofit program, was developed in 1977 by Judge David Soukup in Seattle, Washington (National CASA Association for Children, 2020). He became concerned with the lack of information available to make decisions on behalf of abused and neglected children, especially with the awareness that these judgments could have long-term consequences. Judge Soukup understood that community volunteers could fill a critical gap and be trained and assigned by the court to speak on behalf of the child's best interest in child abuse and neglect proceedings. From its creation, CASA was supported by the National Council of Juvenile and Family Court Judges (NCJFCJ) as a model program and was rapidly established throughout the US. By 1983, 29 states had CASA programs, and within ten years of its inception, 44 states had CASA programs. Across 49 states, there are now 950 CASA programs with over 93,000 volunteers serving nearly 300,000 children each year. Georgia, where Child Advocacy Services, SEGA, Inc. (CASSEGA) the sponsoring agency for CASA and the Ogeechee Visitation Center is located and discussed below, is home to 47 programs.

Although CASA programs differ by State, programs in Georgia, recruit, train, and supervise volunteer laypersons, or CASAs. They advocate for the best interests of foster children involved in juvenile court dependency proceedings (Georgia CASA, 2019). Federal and State law (CAPTA, 42. USC 5106, et.seq; OCGA §15-11-103) requires that a maltreated child who is involved in the court system must be appointed a guardian ad litem (GAL); in Georgia, this individual is not mandated to be a lawyer. When the GAL is not an attorney, the court is required to appoint a CASA volunteer when practical and may also be assigned to a lawyer serving as the child's GAL (O.C.G.A.§15-11-104).

CASA tends to be a respected program among criminal justice professionals, especially judges, and they value having an independent recommendation from a volunteer who has developed a relationship with the child and focuses exclusively on the child's best interest (Litzelfelner, 2008; Osborne, Warner-Doe, \& Lawson, 2019). Research of CASA programs from around the country suggests judges tend to assign CASA volunteers to represent children, with cases deemed as having a high degree of severity (Litzelfelner, 2000; Osborne et al., 2019; Youngclarke et al. 2004). Because of methodological challenges, such as selection bias, CASA is not considered an evidenced-based practice; however, a child appointed a CASA tends to have access to more services, has fewer placements, and has an increased chance of adoption when in need of a permanency plan (Lawson \& Berrick, 2013). 


\section{Child Advocacy Services SEGA, Inc.}

Child Advocacy Services, SEGA, Inc. (CASSEGA) is the sponsoring agency for CASA and the Ogeechee Visitation Center, where the authors serve as the board of directors and the executive director. The mission of CASSEGA is to "recruit, screen, train, and supervise volunteers who advocate for the best interest of abused and neglected children as well as provide supervised family visitation for children who have been placed in foster care in the Ogeechee Judicial Circuit..." which serves five counties. CASSEGA was established in 2002 as CASA Program for the Ogeechee Judicial Circuit, Inc., a 501(c)3 and a charitable organization. Due to both the increased number of children taken into custody and the critical personnel shortage and turnover in the Georgia Division of Children and Family Services (DFCS) offices, foster children were frequently missing their court-ordered visitations with their parents and siblings. DFCS Case Managers, already stretched thin, were often unable to arrange and make-up visits, leaving weeks and sometimes a month or more between visits. The very system meant to protect abused and neglected children were, through uncontrollable circumstances, re-victimizing them. CASA staff and board agreed that this was unfair to the children, but it also created a barrier to successful and timely reunification. In 2016 two visitation centers, located in two counties, were added, and the agency name became CASSEGA, which remains the only program offering supervised visitation in our judicial circuit. Services are provided at no cost to families or DFCS, which removes substantial permanency barriers. At this time, three other CASA programs in Georgia also supplement their services with supervised visitation services.

\section{Organizational Strategies in the Time of COVID-19}

Child Advocacy Services, SEGA, Inc. has found several overarching approaches to be useful in these stressful and uncertain times where "business as usual" has been impossible. Employees are likely struggling with maintaining a work-life balance and with dealing with the distractions that come from working from home. Organizations must realize that working from home during a pandemic is different from "normal" remote work since it is likely the entire family is sequestered together for an extended period. Employees may feel overwhelmed and need a more structured environment. Therefore, management will need to have a system in place to assess how each employee is coping and aid with self-care. Managers cannot micro-manage in this situation and must develop other means of maintaining employee accountability. Managers will need to find small ways to show staff appreciation for their commitment and ability to continue to provide the required level of service.

Small tokens may be meaningful such as thank-you cards, supplies, and other items designed to make coping with COVID-19 more bearable. The organization may need to ease the transition by helping employees acquire needed equipment and supplies for remote work such as printers, desks, paper, toner, etc. While this will be an added expense to the organization it will engender employee good will and likely will allow them to work more efficiently and effectively.

It is likely that in most jurisdictions the courts, the state agencies responsible for children and family services, and other agencies and nonprofit organizations that provide services to children in care are either closed or working remotely. Yet these 
organizations still need to be able to identify new instances of child abuse and maltreatment, monitor children newly reunited with their biological parents, and serve children in foster care (including supervised visitation with their biological parents and siblings). As noted previously, increased instances of child maltreatment can be expected during the pandemic, and it is reasonable to believe that recently reunified parents and children will suffer increased stressors from deteriorating financial conditions and other hardships imposed by shelter-in-place and social distancing requirements. It is also extremely important to foster the connection of these children to their biological parents and to continue to provide parental training. More frequent visits with parents generally means the children will have fewer behavioral problems, a greater chance for successful reunification, be less likely to need psychiatric medication, and be less likely to experience developmental problems (Cantos et al., 1997; McWey \& Mullis, 2004; Nesmith, 2015; Sanchirico \& Jablonka, 2000). Additionally, visitation with siblings who may be placed in a separate foster home or who may not be in care has been found to be important in maintaining what is likely to be the child's longest and closest relationship in life (Wojciak et al., 2018).

A far more difficult problem is identifying new instances of child abuse and maltreatment. Schools and after-school activities are closed so mandated reporters such as teachers and day care workers will be unable to monitor children for signs of abuse. Lack of contact with mandated reporters means that, ironically, a decrease of reports during the pandemic is to be expected, though a subsequent spike may be evident once children return to school and evidence of maltreatment surfaces. Identification of maltreatment or abuse is a complex problem beyond the control of any single organization either within or outside the pandemic. The pandemic serves to compound the problem by temporarily eliminating collaborators from the network. Continued, and strengthened, multi-agency collaboration is needed during this time.

\section{Addressing Barriers to Child Service Provision during a Pandemic}

Identifying appropriate and impactful strategies to address barriers limiting service delivery to children during the COVID-19 pandemic is of the utmost importance. As underscored previously, calls to law enforcement regarding domestic violence incidents have escalated, with increased exposure to abuse and neglect by children stuck at home because of the pandemic (Evans, 2020; Taub, 2020). Solutions must simultaneously consider issues faced by this population more generally as well as how to assist these children while maintaining social distance. Although COVID-19 has exacerbated previously existing barriers to service for children, most notably a significant reduction or suspension of face-to-face contact, innovative strategies to address service provision could assist in resolving or lessening barriers.

Arguably the most impactful innovations to rectify barriers of limited face-to-face contact have come in the form of teleconferencing, which involves synchronous audiovisual communication between multiple individuals. Some of the most widely utilized and well-known teleconferencing software include Zoom, Google Meet and Hangouts, Microsoft Teams, and Webex. Providing services in this environment will be difficult since physical distancing is required. Organizations must first determine how to continue operations and then focus on remote service provision. For all the difficulties in converting an organization to remote work, providing remote services to children 
and families will be far more difficult. However, teleconferencing, once established, may provide a very effective and profitable solution when social distancing is necessary (Hollander \& Carr, 2020; See Liu et al., 2020 for how teleconferencing was helpful in meeting the mental health needs of clients during COVID-19 in China).

While face-to-face visitation and training is preferable, teleconferencing can be used to reinforce familial bonds in the interim while face-to-face visitation is not possible. Application of this software is expansive with state agency case workers, Court Appointed Special Advocates, and Guardians Ad Litem being able to arrange frequent virtual visits with children in foster care to ensure they are healthy and well cared for during shelter-in-place. Moreover, supervised visitation with both parents and siblings can be arranged and monitored by the person in charge of supervision so that the visit can be controlled and recorded if required (this is particularly easy with software such as Zoom). Conferencing can also be used for the purpose of distance education, with one example being direct parental training and coaching as a complement to other online training that may be available. Technology has proven to be effective for delivery of parental training outside the boundaries of the pandemic (Baggett et al., 2017; Baggett et al., 2010).

Tools used to communicate with children and their caregivers can also play a pivotal role for professionals working with children more generally. In some areas "virtual" courts are operating for certain protective hearings and emergency actions may be requested even though most hearings have been continued. One avenue for professionals is identifying and recruiting potential new partners through webinars and meetings hosted by local organizations such as the United Way where discussion of new services and additional resources occurs.

Another approach to overcome barriers is for organizations to use social media to persuade the community that we are responsible for each other and encourage people to report maltreatment or abuse when they see it. Finally, regular meetings using remote conferencing software encourage professionals to engage with each other frequently, perhaps daily. As part of this, it is important that the organization make required information and resources easily available online and encourage knowledge sharing among employees.

Aside from addressing barriers through utilization of technology there is a need to consider additional factors such as the need for training, policy modifications, and fundraising as the impact of working from home might vary between individuals. First, individual development and training should continue to keep employees motivated. If a work-from-home policy does not exist, this would be a great time to develop one. Managers may need specific training to enable them to properly manage remote teams. Second, employee workspaces must be considered as well, particularly if the employee is required to access sensitive information from home which is often the case for child advocates and service workers. Employees will require appropriate equipment, a fast, reliable internet connection, and likely a virtual private network connection to organizational data. Third, though more difficult to achieve and politically dangerous, policy changes could be considered to require wellness checks as a condition of the receipt of certain services during the pandemic. Finally, organizations will need to be creative to finance these continuing operations. Nonprofit organizations provide many of these services and will find fundraising difficult due to the impact of the recession on potential donors. In the interim, new organizations may begin to provide services to 
these families, for example, food banks and agencies administering food stamps, unemployment compensation or other government services. Again, enhanced collaboration and cooperation across multiple, diverse agencies is critical during this period and traditional territorialism must be abandoned for the benefit of children and the community.

\section{Conclusion}

Child services organizations have been faced with unprecedented challenges during the COVID-19 pandemic. These challenges are likely to continue for some time even after the peak of the pandemic. Hopefully, the strategies presented in this paper can assist in overcoming these challenges or at least ameliorating some of the most severe negative effects. Short- and long-term research is needed to fully understand all the barriers to child services during the COVID-19 pandemic, how these barriers are impacting those who require services, and what the best-practices are in overcoming these barriers.

\section{References}

Administration for Children and Families (2019). U.S. Department of Health \& Human Services, Administration for Children and Families, Administration on Children, Youth and Families, Children's Bureau. (2020). Child Maltreatment 2018. Available from https://www.acf.hhs.gov/cb/resource/childmaltreatment-2018

Baggett, K., Davis, B., Feil, E., Sheeber, L., Landry, S., Leve, C., \& Johnson, U. (2017). A randomized controlled trial examination of a remote parenting intervention: Engagement and effects on parenting behavior and child abuse potential. Child Maltreatment, 22(4), 315-323.

Baggett, K. M., Davis, B., Feil, E. G., Sheeber, L. B., Landry, S. H., Carta, J. J., \& Leve, C. (2010). Technologies for expanding the reach of evidence-based interventions: Preliminary results for promoting social-emotional development in early childhood. Topics in Early Child Special Education, 29, 226-238.

Boylan, R. T., \& Ho, V. (2017). The most unkindest cut of all? State spending on health, education, and welfare during recessions. National Tax Journal, 70(2), 329-366.

Brooks-Gunn, J., Schneider, W., \& Waldfogel, J. (2013). The Great Recession and the risk for child maltreatment. Child Abuse \& Neglect, 37(10), 721-729.

Bullen, T., Taplin, S., McArthur, M., Humphreys, C., \& Kertesz, M. (2017). Interventions to improve supervised contact visits between children in out of home care and their parents: a systematic review. Child \& Family Social Work, 22(2), 822-833.

Campbell, A. M. (2020). An increasing risk of family violence during the Covid-19 pandemic: Strengthening community collaborations to save lives. Forensic Science International: Reports, 100089.

Cantos, A. L., Gries, L. T., \& Slis, V. (1997). Behavioral correlates of parental visiting during family foster care. Child Welfare, 76(2), 309.

Cherry, R., \& Wang, C. (2016). The link between male employment and child maltreatment in the U.S., 20002012. Children and Youth Services Review, 66, 117-122.

Connell, C. M., Bergeron, N., Katz, K. H., Saunders, L., \& Tebes, J. K. (2007). Re-referral to child protective services: The influence of child, family, and case characteristics on risk status. Child Abuse \& Neglect, 31(5), 573-588.

Drake, B., \& Pandey, S. (1996). Understanding the relationship between neighborhood poverty and specific types of child maltreatment. Child Abuse \& Neglect, 20(11), 1003-1018.

Evans, S. (2020). CCPD, SPD report recent rise in domestic violence calls. Savannah, Georgia: WTOC Available from: https://www.wtoc.com/2020/04/22/ccpd-spd-report-recent-rise-domestic-violence-calls/.

Felix, S. N., Agnich, L. E., \& Schueths, A. (2017). An evaluation of a Court Appointed Special Advocates (CASA) program in the rural south. Children and Youth Services Review, 83, 48-56.

Georgia CASA, 2019. Available from: https://www.gacasa.org/. 
Graaf, G., Hengeveld-Bidmon, E., Carnochan, S., Radu, P., \& Austin, M. J. (2016). The impact of the great recession on county human-service organizations: A cross-case analysis. Human Service Organizations: Management, Leadership \& Governance, 40(2), 152-169.

Hollander, J. E., \& Carr, B. G. (2020). Virtually perfect? Telemedicine for covid-19. New England Journal of Medicine. https://doi.org/10.1056/NEJMp2003539.

Kahn, J. M., \& Schwalbe, C. (2010). The timing to and risk factors associated with child welfare system recidivism at two decision-making points. Children and Youth Services Review, 32(7), 1035-1044.

Kim, H., Wildeman, C., Jonson-Reid, M., \& Drake, B. (2017). Lifetime prevalence of investigating child maltreatment among US children. American Journal of Public Health, 107(2), 274-280.

Lawson, J., \& Berrick, J. D. (2013). Establishing CASA as an evidence-based practice. Journal of EvidenceBased Social Work, 10(4), 321-337.

Lee, J. S., Romich, J. L., Kang, J. Y., Hook, J. L., \& Marcenko, M. O. (2017). The impact of income on reunification among families with children in out-of-home care. Children and Youth Services Review, 72, 91-99.

Litzelfelner, P. (2000). The effectiveness of CASAs in achieving positive outcomes for children. Child Welfare, 79(2), 179-193.

Litzelfelner, P. (2008). Consumer satisfaction with CASAs (court appointed special advocates). Children and Youth Services Review, 30(2), 173-186.

Liu, S., Yang, L., Zhang, C., Xiang, Y. T., Liu, Z., Hu, S., \& Zhang, B. (2020). Online mental health services in China during the COVID-19 outbreak. The Lancet Psychiatry, 7(4), e17-e18.

Maltais, C., Cyr, C., Parent, G., \& Pascuzzo, K. (2019). Identifying effective interventions for promoting parent engagement and family reunification for children in out-of-home care: A series of meta-analyses. Child Abuse \& Neglect, 88, 362-375.

McWey, L. M., \& Mullis, A. K. (2004). Improving the lives of children in foster care: The impact of supervised visitation. Family Relations, 53(3), 293-300.

National CASA Association for Children, 2020. Available from: https://nationalcasagal.org/.

Nesmith, A. (2015). Factors influencing the regularity of parental visits with children in foster care. Child and Adolescent Social Work Journal, 32(3), 219-228.

Osborne, C., Warner-Doe, H., \& Lawson, J. (2019). Who gets a CASA? Selective characteristics of children appointed a casa advocate. Children and Youth Services Review, 98, 65-71.

Pelton, L. H. (2015). The continuing role of material factors in child maltreatment and placement. Child Abuse and Neglect, 41, 30-39.

Sanchirico, A., \& Jablonka, K. (2000). Keeping foster children connected to their biological parents: The impact of foster parent training and support. Child and Adolescent Social Work Journal, 17(3), 185-203.

Schmidt, S., \& Natanson, H. (2020). With kids stuck at home, ER doctors see more severe cases of child abuse. Available from https://www.washingtonpost.com/education/2020/04/30/child-abuse-reportscoronavirus/.

Schneider, W., Waldfogel, J., \& Brooks-Gunn, J. (2017). The Great Recession and risk for child abuse and neglect. Children and Youth Services Review, 72, 71-81.

Taub, A. (2020). A New Covid-19 Crisis: Domestic Abuse Rises Worldwide. New York, NY: New York Times Available from: https://www.nytimes.com/2020/04/06/world/coronavirus-domestic-violence.html.

U.S. Department of Health \& Human Services, Administration for Children and Families, Administration on Children, Youth and Families, Children's Bureau. (2020). Child Maltreatment 2018. Available from https://www.acf.hhs.gov/cb/research-data-technology /statistics-research/child-maltreatment.

Wojciak, A. S., Range, B. P., Gutierrez, D. M., Hough, N. A., \& Gamboni, C. M. (2018). Sibling relationship in foster care: Foster parent perspective. Journal of Family Issues, 39(9), 2590-2614.

Woodall, C. (2020). As hospitals see more severe child abuse injuries during coronavirus, 'the worst is yet to come'. USA Today. Available from: https://www.usatoday.com/story/news/nation/2020/05/13/hospitalsseeing-more-severe-child-abuse-injuries-during-coronavirus/3116395001/?fbclid=IwAR05nxGO0 IrpSzRHZ7vrZe5DsBgqm9gKf5xQj7XEMvBjt_gzJYCOJ-Y2aj0.

Yang, M. (2015). The effect of material hardship on child protective service involvement. Child Abuse \& Neglect, 41, 113-125.

Yi, Y., \& Wildeman, C. (2018). Can foster care interventions diminish justice system inequality? The Future of Children, 28(1), 37-58.

Youngclarke, D., Ramos, K. D., \& Granger-Merkle, L. (2004). A systematic review of the impact of court appointed special advocates. Journal of the Center for Families, Children, \& the Courts, 5, 109-126.

Publisher's Note Springer Nature remains neutral with regard to jurisdictional claims in published maps and institutional affiliations. 
Chad Posick , Ph.D. is an Associate Professor and the Graduate Director in the Department of Criminal Justice and Criminology at Georgia Southern University. His research focuses on the causes and consequences of victimization, violence prevention, and biopsychosocial theory development. He is a member of the Scholars Strategy Network and serves on the Board of Directors for Child Advocacy Services SEGA, Inc.

April M. Schueths , Ph.D., LCSW, is an associate professor in the Department of Sociology and Anthropology at Georgia Southern University. Within the broad area of social inequality, her research focuses on the intersection of race with family relations and immigration policy, education, social services, and health. She has been a board member of Child Advocacy Services, Southeast Georgia, Inc. (CASSEGA) since 2011 and is the current board chair.

Cary Christian , Ph.D. is an Associate Professor in the Department of Public and Non-Profit Studies at Georgia Southern University. His research interests are in public budgeting, finance, and policy. He is a member of the Board of Directors for Child Advocacy Services SEGA, Inc.

Jonathan Grubb , Ph.D. is an Assistant Professor in the Department of Criminal Justice and Criminology at Georgia Southern University. He conducts research on attitudes and perceptions of victim service providers, barriers to service provision, victimological theory, and the spatiotemporal clustering of crime. Jonathan serves on the Board of Directors for Child Advocacy Services SEGA, Inc.

Suzanne E. Christian, CFE, is the Executive Director for Child Advocacy Services SEGA, Inc. that oversees the Court Appointed Special Advocates (CASA) Program and the Ogeechee Visitation Centers.

\section{Affiliations}

\section{Chad Posick $^{1}$ - April A. Schueths ${ }^{2} \cdot$ Cary Christian $^{3}$ - Jonathan A. Grubb ${ }^{1}$. Suzanne E. Christian ${ }^{4}$}

1 Department of Criminal Justice \& Criminology, Georgia Southern University, Hinesville, GA, USA

2 Department of Sociology \& Anthropology, Georgia Southern University, Hinesville, GA, USA

3 Department of Non-Profit Studies, Georgia Southern University, Hinesville, GA, USA

4 Child Advocacy Services SEGA, Inc., Statesboro, GA, USA 